Joaquín Silva

Facultad de Teología

Pontificia Universidad Católica de Chile

\title{
Dios en el pensamiento de M. Heidegger. La interpretación de Welte
}

Welte escribió al menos 20 textos sobre Heidegger (1). Estos van desde el año 1947 al año 1977. Las cuestiones que estos textos abordan son algunas de carácter general, como, por ejemplo, las posibilidades y límites de la ontología; otros tratan

(1) "Remarques sur 1'ontologie de Heidegger. In: Revue des sciences philosophiques et theologiques" 31 (1947) 379-393; "Die Lichtung des Seins. Bemerkungen zur Ontologie Martin Heideggers", Wort und Wahrheit 3 (1948), 401-412; "Zu Martin Heideggers 70. Geburtstag. Eine christliche Erwägung”, Christlicher Sonntag 11 (1959) 306; "Der Weg der Heimat", en: Stadt Messkirch (ed.), Martin Heidegger 26. September 1959, Aker, Messkirch 1960, 3-13; "Heidegger und die Theologie. Zum 75. Geburtstag von Martin Heidegger", Der christliche Sonntag 16 (1964) 310-311; "Die Gottesfrage im Denken Martin Heideggers", en: B. Welte, Auf der Spur des Ewigen, op. cit., 262276; anteriormente, en: F. Pöggeler (ed.), Innerlichkeit und Erziehung. In memoriam Gustav Siewerth, Herder, Freiburg-Basel-Wien 1964, 177-192. [La cuestión de Dios en el pensamiento de Martin Heidegger. In: Teología 6 (1968), S. 25-42]; "Thomas von Aquin und Heideggers Gedanke von der Seinsgeschichte", en: B. Welte, Zeit und Geheimnis..., op. cit., 203-218 [anteriormente, bajo el título "Rückblick auf die Metaphysik", en: Wort und Wahrheit 22 (1967) 747-757; traduccion francesa: La métaphysique de Saint Thomas d'Aquin et la pensée de l'histoire de l'être chez Heidegger. In: Revue des sciences philosophiques et théologiques 50 (1966), S. 601-614]; "Heidegger 80 Jahre", Christ in der Gegenwart 21 (1969) 308; "La question de Dieu dans la pensée de Heidegger", Revista Portuguesa de Filosofia 26 (1970), S. 147-165; "Préface”, en: F. Couturier, Monde et être chez. Heidegger, Les presses de 1'Université de Montréal Montreal 1971, VII-XI; "Das Denken. Martin Heidegger 85 Jahre", Christ in der Gegenwart 26 (1974) 302; "Gott im Denken Heideggers"; en: B. Welte, Zeit und Geheimnis, op. cit., 258-280; "Denken und Sein. Gedanken zu Martin Heideggers Werk und Wirkung", Herderkorrespondenz 30 (1976) 373-377; "Suchen und Finden. Ansprache zur Beisetzung am 28. Mai 1976", en: G. Neske (ed.), Erinnerung an Martin Heidegger, Neske, Pfullingen, 1977, 253-256 [Buscar y encontrar. Alocución en el sepelio de Martin Heidegger", Universitas 14 (1977), S. 247-251]; “O Pensamento de Martin Heidegger e as ideologias. In: S. Ladusans (ed.), Pensamento parcial e total, São Paulo 1977, 99114; "Erinnerung an ein spätes Gespräch", en: : G. Neske (ed.), Erinnerung an Martin Heidegger, Neske, Pfullingen, 1977, 249-252; "Auf der Suche nach dem verlorenen Ursprung. Essay über ein Gedicht von Karl Krolow und einen Gedanken von Martin Heidegger". en: B. Welte, Zwischen Zeit und Ewigkeit. Abhandlungen und Versuche, Freiburg/Br.: Herder 1982, S. 112-120 [La búsqueda del origen perdido. Reflexiones sobre un pensamiento de Martin Heidegger y un poema de Karl Krolow. Trad. R. Vergara und J. E. Rivera. en: Philosophica. Revista del Instituto de Filosofía de la Universidad Católica de Valparaíso 4 (1981) 169-175]; "Bemerkungen zum Seinsbegriff Heideggers. Für den Druck vorbereitet von Stephanie Bohlen”, en: K. Hemmerle (ed.), Fragend und lehrend den Glauben weit machen. Zum Werk Bernhard Weltes anläßlich seines 80. Geburtstags, Schnell \& Steiner, Freiburg 1987, 133-138; "Die Hölderlin-Verse zur Beisetzung Heideggers: Versuch einer Deutung"; en: Forum 18 (1997) 10-16; "Nach einem neuen Zuspruch Gottes suchen" en: Christ in der Gegenwart 29 (1977) 374. 
de algunos de temas característicos en el pensamiento heideggeriano, como por ejemplo: "la luz del ser", la "historia del ser", el "análisis fenomenológico del ser", etc.; en otros escritos Welte busca establecer una relación entre el pensamiento de Heidegger y las tradiciones filosóficas especialmente significativas para su pensamiento, como lo fueron Tomás de Aquino, Eckhart, Hegel y Nietzsche. Y también nos encontramos con otros textos escritos con ocasión de los cumpleaños de Heidegger: estos parten el año 1959, cuando Heidegger ha cumplido 70 años, y luego se suceden cada cinco años, hasta un texto del año 1974, cuando Heidegger ha cumplido ya 85 años. Aunque la brevedad, generalidad y carácter laudatorio de estos textos no permiten un análisis detallado de la interpretación que hace Welte del pensamiento de Heidegger, se trata de reflexiones que en profundidad y sintéticamente buscan pensar en aquello que Heidegger ha propuesto pensar.

En nuestra presentación tendremos en cuenta gran parte de estos textos en los que Welte ha escrito sobre Heidegger, pero muy especialmente aquel en que más sistemáticamente se aborda la cuestión de Dios y que Welte, justamente, publicó bajo ese título, como resultado de su último seminario como profesor catedrático en la Universidad de Freiburg. Entonces, como él mismo se lo confesara a Heidegger, "quería terminar esa actividad con el mismo pensamiento en cuya cercanía la había comenzado" (2).

El interés particular por este texto del año 1975, por cierto, radica en la cuestión misma de la que trata. Sin embargo, el contexto es también importante y nos entrega valiosas claves para su interpretación. Primero: es un texto que Welte escribe al finalizar su carrera académica en la Universidad de Freiburg, lo que le permitió -como él mismo lo afirma- repensar y revisar algunas cosas que había escrito antes al respecto" (3). En este sentido, el texto en cuestión nos ofrece una referencia más madura y segura de la interpretación que a lo largo de los años Welte fue haciendo de Heidegger. Segundo: esta base "segura", lo es de un modo que Welte y Heidegger comparten plenamente; se trata de una seguridad que no es constatable ni objetivable. Por ello, con humildad y aguda inteligencia, Welte le confiesa a Heide-

(2) Carta de Benhard Welte a Martin Heidegger a, Freiburg, 23 de julio de 1973. Freiburg, 28 de marzo de 1966. En: Universidad Iberoamericana (ed.), Martin Heidegger. Cartas a Max Müller y Bernhard Welte, Universidad Iberoamericana, México 1996, p. 101.

El primer trabajo de Welte respecto de Dios en el pensamiento de Heidegger data del año 1964 y se tituló "Die Gottesfrage im Denken Martin Heideggers". Fue publicado en: F. Pöggeler (ed.), Innerlichkeit und Erziehung. In memoriam Gustav Siewerth, Herder, Freiburg-Basel-Wien 1964, 177-192, y luego en: Welte, B., Auf der spur des Ewigen: Philsophische Abhandlugen über verschiedene Gegenstände der Religion und der Theologie, Herder, Freiburg 1965, 262-276; al español fue traducido con el título "La cuestión de Dios en el pensamiento de Martin Heidegger" y publicado por la Revista Teología de la Facultad de Teología del Pontificia Universidad Católica Argentina: Teología 6 (1968), 25-42.

El segundo trabajo en que expresamente abordó nuestro tema data del año 1970 y fue publicado bajo el título "La question de Dieu dans la pensée de Heidegger" en la Revista Portuguesa de Filosofia 26 (1971) 147-165.

Y el tercero y último trabajo sobre la cuestión de Dios en Heidegger, es este del año 1975 en el que recoge muchos de los planteamientos anteriores, pero revisados, corregidos y desarrollados por el mismo Welte.

(3) Carta de Benhard Welte a Martin Heidegger a, Freiburg, 23 de julio de 1973. En: Universidad Iberoamericana (ed.), Martin Heidegger. Cartas a Max Müller y Bernhard Welte, Universidad Iberoamericana, México 1996, p. 102. 
gger: "ciertamente no estoy seguro si con mi interpretación siempre estoy en el camino correcto. Pero, tal vez, es más importante pensar y pensar-con, que una seguridad constatable. Eso es lo que aprendí de usted -además de otras muchas cosas" (4).

Pero hay una tercera razón por la que me ha parecido particularmente importante este texto. Desde julio del año 1973 Welte había servido de mediador de una petición hecha a Heidegger desde Brasil. Allí los jesuitas, en particular el padre Ladusans, querían publicar una colección sobre filosofía moderna que incluyera una autobiografía filosófica de Heidegger. Con la insistencia propia de los hijos de Ignacio, a través de Welte buscaron una y otra vez que Heidegger accediera a la petición. Pero, Heidegger fue más insistente que el padre Ladusans: apreciando el interés de los brasileños y la mediación de su compatriota, volvió a rechazar la petición. Sin embargo, le escribió a Welte diciéndo: "hay una alternativa totalmente válida: su propio texto y su forma de co-pensar". Es decir, Heidegger consideró que el texto de Welte válidamente se podía ofrecer como una alternativa a su autobiografía filosófica. ¿Con ello se quiso liberar, simplemente, de la insistencia del Padre jesuita? Lo más probable es que no, puesto que con independencia de estas circunstancias, Heidegger ya le había escrito a Welte lo siguiente: "Le agradezco mucho haberme mandado el texto que resume densamente las reflexiones de su último seminario en esta Universidad y que está dedicado a mi pensamiento. Su co-pensar minucioso y cuidadoso es tan satisfactorio como extraordinario. Por lo general suelen clasificar mis intentos precozmente en alguna categoría o aprovecharse de ellos de manera apologética. Usted sigue claramente una línea de mi pensar en sus estadios cambiantes" (5).

Probablemente, este mutuo aprecio intelectual reforzó en ellos la cercanía que ya sentían por el hecho de provenir de una misma tierra: el pueblo de Messkirch. Es sabido que durante los últimos años de vida esta cercanía se intensificó y que en la tarde del 24 de enero de 1976, cuatro meses antes de su muerte, Heidegger mismo pidió a Welte que este hablara en su entierro. Y como afirma Welte: "él no podía sino esperar de mí una palabra religiosa en su tumba" (6). En efecto, el tema de estos últimos años había sido uno y el mismo: Dios y las condiciones de posibilidad para articular un pensamiento respecto de Él. La teología mística especulativa, particularmente la del maestro Eckhart, estará al centro de sus conversaciones y ofrecerá a ambos interesantes pistas para seguir pensando (7).

(4) Carta de Benhard Welte a Martin Heidegger a, Freiburg, 31 de julio de 1974. En: Universidad Iberoamericana (ed.), Martin Heidegger. Cartas a Max Müller y Bernhard Welte, Universidad Iberoamericana, México 1996, p. 104.

(5) Carta de Martin Heidegger a Benhard Welte, Freiburg, 13 de agosto de 1974. En: Universidad Iberoamericana (ed.), Martin Heidegger. Cartas a Max Müller y Bernhard Welte, Universidad Iberoamericana, México 1996, pp. 104-105.

(6) Bernhard Welte, Mi último encuentro con Heidegger [Título original: Dialektik der Liebe. Josef Knech - Frankfurt am Main - Versión castellana: "Dialéctica del amor", Bernhard Welte, págs. 75-84, traducción de Néstor Corona. Editorial Docencia]. Versión electrónica en: http://www. heideggeriana. com. ar/comentarios/welte. htm

(7) Así relata Welte esta última conversación con Heidegger: "También hablamos sobre las lecciones que entonces yo dictaba. Eran lecciones sobre Meister Eckhart, y, con ello, nuevamente estábamos en contexto religioso. Desde hacía tiempo Heidegger tenía profundo conocimiento 
Por cierto, las razones histórico-biográficas indicadas no aseguran nada respecto de la pertinencia y validez de la interpretación que hace Welte del pensamiento de Heidegger acerca de Dios. Sin embargo, ellas constituyen motivos suficientes como para pensar que estamos ante un texto que, justamente por ser "tan satisfactorio como extraordinario", invita a seguir pensando, cuestión que aquí hacemos revisando y profundizando varias de las cuestiones que inicialmente traté en mi libro $L a$ verdadera religión.

Consideremos primero cuáles son las principales ideas que Welte expone en este texto del año 1975, para luego reflexionar sobre aquellas que se nos muestren como las más interesantes.

\section{UNA MIRADA AL CONJUNTO}

El primero de los once pasos en que Welte articula su texto del año 1975 trata del punto de partida metódico del pensamiento de Heidegger, y este lo reconoce en el conocido $§ 7$ de Ser y Tiempo, en particular en la invitacion que hace allí Heidegger a volver "a las cosas mismas" (8). Esta perspectiva le permite a Welte entrar empáticamente en el pensamiento de Heidegger y desde esa totalidad (Wagnis des Ganzen) preguntarse si algo así como "Dios" se muestra y cómo lo hace. El lenguaje, afirma en este contexto, es aquello que permite sacar al fenómeno del ocultamiento en el que se muestra (9).

En un segundo momento, Welte intenta pensar aquello en torno a la cual gira -según él- todo el pensamiento de Heidegger; a saber, el ser de todo aquello que se muestra, el ser de todo Sich - Zeigendes. El ser de todo ente es, primero, aquello oculto y olvidado, pero siempre como aquello que es dado, que está ahí, que es. La fenomenología como ontología justamente pretenderá descubrir, reconocer y decir el ser del ente, oculto y olvidado. En el análisis de la existencia humana -como también Welte lo había expresado en su texto del año 1964- Heidegger logra descubrir y desprender el lugar (el "da"), donde algo así como el ser se muestra y manifiesta. Sin embargo, "tratando de desprender el ser y su sentido en la región del da-sein humano, Heidegger encuentra en primer término, no el ser, sino la nada" (10). Desde esta experiencia aniquiladora de la nada se muestra aquello que es, como lo admirable e incomprensible por sí mismo, como dirá Heidegger, como el "milagro

de Meister Eckhart. Y así, en el curso de aquel diálogo, preguntó meditadamente y con total seguridad del sentido de la pregunta, sobre la soledad en el sentido de Meister Eckhart. El tema tenía una oculta actualidad en aquella extraña hora. En el espacio también flotaba el pensamiento de Eckhart según el cual Dios es igual a la nada. Estos pensamientos de Eckhart, junto con lo hogareño de la tierra natal y con la cercanía de la muerte, hicieron que aquella hora configurara el ámbito en que de manera peculiar se correspondían Cielo y Tierra, Mortales e Inmortales. Lo reunido del Cuarteto palpitaba en aquella hora vespertina y se hallaba convocado en torno de aquel a quien la muerte ya dirigía su mirada" (En: B. Welte, Mi último encuentro con Heidegger, op. cit.).

(8) Cf. B. Welte, "Gott im Denken Heideggers", en: Zeit und Geheimnis..., op. cit., 259. Véase también el texto del año 1964, "La cuestión de Dios...", Teología 12 (1968) 27.

(9) Cf. B. Welte, "Gott im Denken Heideggers", en: Zeit und Geheimnis..., op. cit., 260.

(10) B. Welte, "La cuestión de Dios...”, Teología 12 (1968) 30. 
de todos los milagros" (11). Welte piensa que la diferencia ontológica se manifiesta justamente en este reconocimiento de lo dado del ser del ente.

En un tercer momento, Welte se pregunta por el ser que, en un primer momento, se ha manifestado como nada: ¿qué es aquello? ¿es acaso Dios? Podría ser fácil afirmar aquí con Tomás de Aquino que aquel ser es el ipsum esse, el ser que la metafísica reconoce como Dios. Sin embargo, piensa Welte, no corresponde forzar el pensamiento de Heidegger a un tal concordismo. Justamente con afirmaciones respecto del ser como Es ist es selbst, pareciera que Heidegger ha querido evitar que el ser sea simplemente asimilado a las ideas corrientes del ser y de Dios. Por ello, más explícitamente dirá en Carta sobre el Humanismo, el ser "no es Dios ni algún fundamento del mundo" (12).

En un cuarto paso, Welte expone lo que llama la intuición decisiva del método fenomenológico y del pensamiento de Heidegger: la comprensión del ser como como luz y verdad. En efecto el ser no es un "en-sí" sino que él "se ilumina, se da y ofrece a sí mismo y a todo ente". Y este darse y ofrecerse es también posible por cuanto el ser tiene alguien a quien se da y ofrece de modo privilegiado: el hombre.

Este acontecer del descubrimiento e iluminación del ser, su salida desde el ocultamiento y la disimulación, y también su llegada al hombre y su apropiación se comprenderá -en un quinto paso-, como Ereignis, como "acontecimiento-apropiación" (13), como destino que acontece en la historia, como historia del ser (14).

Al considerar el ser en su manifestación histórica, Heidegger logra una nueva interpretación de la historia occidental. Es lo que Welte intenta establecer en un sexto paso de su argumentación, recordando para ello las reflexiones en las que Heidegger muestra cómo en occidente el destino del ser ha sido la historia de su olvido, la historia de su ocultamiento y, especialmente, la historia de un pensar que se ha vuelto cada vez más hacia el ente, cada vez más hacia lo que, al menos en parte, es posible de objetivar, representar y manipular.

Por cierto, esta historia de olvido del ser -expone Welte en un séptimo momento- ha tenido consecuencias decisivas respecto de la pregunta por Dios. En efecto, Welte reconoce en una de las afirmaciones más centrales de la metafísica occidental, la de Dios como ente supremo, el principio de su propia negación y, por tanto, el de su superación. En efecto, en el pensamiento metafísico Dios es representado y asegurado en cuanto ente. Y lo es sobre todo en cuanto causa; finalmente, como lo hace notar Heidegger, en cuanto causa sui (15).

Así, Welte llega al octavo paso de su estudio, en donde intenta responder a la pregunta por la presencia-ausencia de la pregunta por Dios, en una era en que, según Heidegger, junto con la hegemonía de la técnica, ha concluido la época de la metafísica, es decir, la época de un pensamiento que representa y dispone, en la que, por

(11) M. Heidegger, Was ist Metaphysik?, Frankfurt a. M. ${ }^{5} 1949$, Nachwort, s. 43 (citado por B. Welte, "Gott im Denken Heideggers", en: Zeit und Geheimnis..., op. cit., 262).

(12) Cf. B. Welte, "Gott im Denken Heideggers", en: Zeit und Geheimnis..., op. cit., 264-265.

(13) Cf. B. Welte, "La cuestión de Dios...", Teología 12 (1968) 34.

(14) Cf. B. Welte, "Gott im Denken Heideggers", en: Zeit und Geheimnis..., op. cit., 266-267.

(15) B. Welte, "Gott im Denken Heideggers", en: Zeit und Geheimnis..., op. cit., 268; cf. B. Welte, "La cuestión de Dios en el pensamiento de Martin Heidegger", Teología 12 (1968) 37. 
consiguiente, la ausencia de Dios se expande y consolida; pero que, a su vez, es una época en la que de profundis muchas veces se clama al Dios escondido, olvidado y negado.

En un noveno paso, Welte afirma que Heidegger no se queda en la sola constatación de la ausencia de Dios, del clamor de profundis que ella pueda suscitar. Su pensamiento avanza hacia Dios, sin por ello negar su ausencia u ocultamiento. Esto lo hace intentando superar la metafísica y, con ella, al Dios de la metafísica. Esta superación de la metafísica será -afirma Welte- "preparación de la esperada venida del Dios aún escondido y extrañado" (16).

Continúa Welte su aproximación a la cuestión de Dios mostrando -en un décimo paso- cómo en la cercanía del poeta Hölderlin el pensamiento de Heidegger adquirió una nueva dimensión. A luz de este poeta se le hará posible hablar del ser con nuevas palabras: con las palabras de lo santo, de lo divino y también con la palabra de Dios. En todo ello, dirá Heidegger, "lo santo aparece, pero Dios permanece lejos" (17).

En un último paso Welte introduce el concepto Winken, a través del cual Heidegger habría querido expresar la experiencia de signos-señales de lo santo y de lo divino que nos indican la salvación, la espera de Dios en la misma región de la nada. En la medida que enseñan aquello, estos signos nos permiten tanto reconocer la presencia de Dios, como soportar su ocultamiento y ausencia. Se trata -afirma Welte- de "mensaje" alentadores, que viniendo del ser nuevamente nos remiten a su misterio como el lugar de una epifanía posible, querida y esperada del Dios divino" (18).

En este pensar la cuestión de Dios en Heidegger, advierte Welte, debemos "proceder con precaución y cuidarnos de querer fijar a Heidegger en una posición que él quizás no había tomado más que como una etapa de un camino, o también de un Holzweg, que lleva más lejos" (19). Con todo, acogiendo la advertencia de Welte, y guiados por él, nos preguntamos ahora por los principales impulsos que el pensamiento de Heidegger nos ofrece respecto de la pregunta por Dios.

\section{EL SER EN SU CONCRECIÓN HISTÓRICA}

La "luz del ser" de la que hablábamos más arriba se nos manifiesta como condición de posibilidad para llegar a ser auténticos sujetos en el acontecimiento de una posible revelación del Dios divino (20). En efecto, esta "luz del ser" ya resplandece en las preguntas y constataciones más originales de los niños, y que adquieren formas lingüísticas del tipo: “¿qué es esto?”; o "esto y aquello son”; o bien, "todo

(16) B. Welte, "Gott im Denken Heideggers", en: Zeit und Geheimnis, 272.

(17) M. Heidegger, Erläuterungen zu Hölderlins Dichtung, s. 25 (citado por B. Welte, "Gott im Denken Heideggers", en: Zeit und Geheimnis, 275).

(18) B. Welte, "Gott im Denken Heideggers", en: Zeit und Geheimnis, 278.

(19) Welte, B., "La cuestión de Dios en el pensamiento de Martin Heidegger", Teología 12 (1968) 25 26.

(20) B. Welte, Heilsverständnis, 41 y ss. Véase también: "Gott im Denken Heideggers", en: Zeit und Geheimnis, 259-267. 
ello es". Recién en esta luz del ser el hombre se constituye como tal, incluso antes de que pueda nombrar o asir en el pensamiento aquello que "es". En esta "luz del ser" que se manifiesta al hombre, y en la cual él se va reconociendo también a sí mismo y se va familiarizando con el ser de todas las cosas, se funda cualquier comprensión que él pueda tener de aquello que es (21). Preguntar "¿qué es esto o aquello?", supone la experiencia de que esto o aquello "es" (22).

La "luz del ser" y aquellas capacidades de comprensión que en ella habitan, sin embargo, "no se nos ofrecen en una pureza abstracta, sino que siempre en sus respectivas modificaciones históricas (23). Esto significa que el fundamento trascendental de nuestra comprensión del ser, como también nuestro horizonte de comprensión, se muestran siempre en modificaciones históricas concretas. Por este motivo, explicará Welte, es posible distinguir épocas históricas, en las cuales los hombres comprenden de modo peculiar y propio la totalidad de lo que es, la totalidad de su ser en el mundo. Estas diferentes épocas históricas -trátese de la antigüedad, del medievo, o de la época moderna- son siempre únicas y determinan el conjunto del pensamiento y de la vida en cada época y tiempo histórico (24). La "historia del ser" permite cuestionar todo sistema conceptual que quiera abstraerse de los condicionamientos y avatares de la historia.

La particularidad y singularidad de cada época histórica, la historicidad de la comprensión del ser y de toda comprensión humana, sin embargo, se sitúan siempre sobre un "fundamento trascendental que ninguna historicidad puede destruir, sino que, al contrario, es capaz de sostenerla y posibilitarla" (25). Este fundamento trascendental, afirma Welte, no solo se muestra en el hecho de que en todo tiempo histórico los hombres se han podido comprender entre sí, sino más aún cuando ello no lo han podido hacer y se ha debilitado o destruido la mutua comprensión: "la negatividad se funda -como toda negatividad- en una positividad" (26). De allí que cada época histórica, en su singularidad y determinación, con sus logros y fracasos, viva siempre sobre este fundamento que la trasciende a sí misma, en cuanto le ofrece la posibilidad de entender y vivir su propia particularidad en un horizonte de comprensión mayor. En este sentido, "cada modo de comprensión epocal e histórico se deberá pensar como una modificación de la capacidad trascendental de comprender, pero no como su negación" (27).

(21) “Dieses Primum, das sich uns in der immer schon waltenden Vertrautheit mit dem 'ist' und dem 'Sein' offenbart, zeigt sich nun seinerseits als die lebendige Wurzel und als der ermöglichende Grund, der alles Vermögen des Mitvollzugs in sich birgt und aus sich entlässt" (B. Welte, Heilsverstándnis, 43).

(22) Como afirma Welte, "Alles Verständliche und zu Verstehende und ans Verstehen Appellierende ist von vornherein schon aus diesem 'ist' gebildet, es ist dessen übergehen und übergegangensein, und darin ist es verständlich und kann es verstanden werden" (Heilsverständnis, 45).

(23) B. Welte, Heilsverständnis, 51. Véase también, B. Welte, “Hegel theologischer Entwurf...”, 104124.

(24) Esta idea, como el mismo Welte lo hace ver, tiene un correlato en la idea de Seinsgeschichte de M. Heidegger (Cf. B. Welte, B. Welte, "Ein Vorschlag zur Methode der Theologie heute", en: Auf der Spur des Ewigen, 417, nota 417).

(25) B. Welte, Heilsverständnis, 52.

(26) B. Welte, Heilsverständnis, 53.

(27) B. Welte, Heilsverständnis, 53. De este modo, entre otros, Welte se distancia de un mero "historicismo" en la comprensión de la verdad (Cf. B. Welte, “Hegel theologischer Entwurf...”, 135-142). 
La negatividad de una determinada época histórica, sus límites y negaciones, también dicen. De este modo, afirma Welte, "la falta de Dios, desde la cual se constituye el límite, no es nada, sino más bien, ella misma aparece y se hace perceptible" (28). Aparece como ausencia de Dios, como muerte de Dios -en el caso de Nietzsche, por ejemplo-, pero, al mismo tiempo, como un grito de profundis, como búsqueda de Dios. En el entierro de Heidegger, Welte decía: ese "clamor que Heidegger advirtió en Nietzsche era ciertamente su propio clamor".

A mi entender, la lectura que Welte hace de Heidegger nos invita a reconocer la cuestión de Dios no solo en el ámbito de la pregunta por el ser -cuestión por cierto no poco importante-, sino que también en el contexto de una historia del ser en la que el hombre se va reconociendo a sí mismo y el mundo que habita en una multiplicidad de experiencias que lo interrogan constantemente y en las cuales puede llegar a experimentar al Dios divino, incluso en una época en la cual se hace más patente su olvido y ocultamiento, pero también la esperanza de su manifestación.

\section{EL RETORNO AL FUNDAMENTO DE LA METAFÍSICA}

Una segunda cuestión que Welte destaca con mucha agudeza en sus diversos escritos sobre Heidegger es que en esta historia del ser uno de los rasgos quizás más propios de nuestra época está constituido por aquella diferencia fenomenológica entre el Dios poderoso, infinito, incondicional, misterioso, inefable, etc., al que podemos llegar por medio del pensamiento, y el Dios divino. Como decíamos más arriba, en la filosofía, particularmente en el pensamiento metafísico, el nombre de Dios será causa sui. Pero, como escribe Heidegger en un texto ya muchas veces citado: "el hombre no puede orar ante este Dios ni ofrecerle sacrificios. Ante la causa sui el hombre no puede ni caer de rodillas lleno de sobrecogimiento, ni tocar instrumentos musicales y danzar" (29).

Welte piensa que la crítica de M. Heidegger a la metafísica, distinta en sus fundamentos a la formulada por el pensamiento positivista moderno (30), debe comprenderse, primero, como un reconocimiento y una búsqueda de lo "no pensado"

(28) B. Welte, "Gott im Denken Heideggers", en: Zeit und Geheimnis, 270. Welte indica que esta idea de la "falta de Dios" (Fehl Gottes), Heidegger la toma de Hölderlin, y le sirve para explicitar aquello que sucede cuando Dios sigue siendo nombrado, sin que el nombrarlo tenga ya la fuerza original de lo supremo, de lo santo, de lo determinante del tiempo y de la historia (cf. p. 269).

(29) M. Heidegger, Die onto-theo-logische Verfassung der Metaphysik, en: Identität und Differenz, Pfullingen 1957, 70 (citado por B. Welte, Filosofía de la Religión, 76). Véase también: "Die Gottesfrage im Denken Martin Heideggers", en: Auf der Spur des Ewigen, 272-273; "Denken und Sein. Gedanken zu Martin Heideggers Werk und Wirkung”, Herderkorrespondenz 30 (1976) 375376.

(30) En un artículo sobre "la crisis de las afirmaciones dogmáticas respecto de Cristo", Welte considera que, en el sentido de Heidegger, tipos de pensamiento positivistas como los de Karl R. Popper o Rudolf Carnap, aunque sean ellos mismos críticos respecto de la metafísica, representan, más bien, una expresión acabada de ella: afirmaciones que no sean falseables o verificables, según el modelo de las ciencias empíricas, caen bajo la sospecha de no tener sentido real (Cf. B. Welte, "Die Krisis der dogmatischen Christussaussagen", en: Zeit und Geheimnis, 301 y s.; véase también: B. Welte, "Jesus Christus und die Theologie", en: J. Sauer (ed.), Wer ist Jesus Christus?, Herder, Freiburg-Basel-Wien 1977, 159 y ss.). 
(Ungedachte) en ella, puesto que allí es posible encontrar la fuente de lo pensado. Como en todo sistema, también en la metafísica se parte de presupuestos no pensados, que determinan todo lo pensado en dicho sistema (31). Esto "no pensado no está constituido, simplemente, por conceptos y pensamientos que subyacen a un determinado sistema por el "modo en que la totalidad de aquello que es se le acerca e ilumina" (32).

A nuestro entender, cuando Heidegger y Welte hablan de metafísica no están pensando tanto en determinados contenidos del pensamiento, cuanto en un modo de pensar, que ha seguido el destino propio del pensamiento occidental -desde los presocráticos hasta Nietzsche- y que estaría justamente dado por el olvido de la diferencia entre el ser y el ente; esto es, por la imposibilidad del pensamiento para reconocer y experimentar el ser que se manifiesta en cuanto es, por la concentración unilateral del pensamiento en la entidad del ente, por la atención exclusiva al qué de cuanto es. Afirma Heidegger: "Aunque la metafísica se representa el ente en su ser y, así, piensa el ser del ente, ella no piensa la diferencia de ambos. La metafísica no pregunta por la verdad del ser mismo" (33).

Ahora bien, el destino del pensamiento occidental se ha realizado y desplegado en todas sus posibilidades, en la medida que ha puesto al ente como objeto del saber: "ahora, escribe Welte en un texto sobre la historia del ser en Tomás de Aquino y Heidegger, progresivamente, el ente, incluso el ente como totalidad, es comprendido y fijado en conceptos. Y en la medida en que esto ocurre, el ente queda entregado a la manipulación y disposición del hombre. El pensamiento se transforma en pensamiento representativo, en cuanto mediante el recurso al concepto él puede representar ante sí la totalidad del ente y, de este modo, lo puede determinar y asegurar" (34). De este modo, escribe Welte en el texto sobre Dios en el pensamiento de Heidegger, el pensamiento "comienza a hacerse más poderoso que el Dios de la metafísica. Y, en este hacerse más poderoso, el pensamiento comienza a determinar y a disponer de los entes y, así, también del ente supremo, del Dios de la metafísica. Una vez iniciado este proceso, resulta consecuente que,

(31) Cf. B. Welte, "Thomas von Aquin und Heideggers Gedanke von der Seinsgeschichte", en: Zeit und Geheimnis, 203-204. Los textos de M. Heidegger a los que Welte hace expresa referencia en este escrito del año 1967, son los siguientes: Platons Lehre von der Wahrheit, Bern 1947; Vorträge und Aufsätze, Pfullingen 1954; Identität und Differenz, Pfullingen 1957; Nietzsche I y II (Pfullingen 1961).

(32) B. Welte, "Thomas von Aquin und Heideggers Gedanke von der Seinsgeschichte", en: Zeit und Geheimnis, 204.

(33) M. Heidegger, Brief über den "Humanismus", en: M. Heidegger, Wegmarken, Vittorio Klostermann, Frankfurt a. M. ${ }^{2} 1978$, 320. Textos en los que Welte aborda esta cuestión de un modo semejante al de Heidegger: B. Welte, "Die Krisis der dogmatischen Christusaussagen”, en: Zeit und Geheimnis, 312; B. Welte, "Die Lehrformel von Nikaia und die abendländische Metaphysik", en: B. Welte (ed.), Zur Frühgeschichte der Christologie. Ihre biblischen Anfänge und die Lehrformel von Nikaia, Herder, Freiburg-Basel-Wien 1970, 111; B. Welte, "Denken und Sein. Gedanken zu Martin Heideggers Werk und Wirkung", Herderkorrespondenz 30 (1976) 374; B. Welte, "Atheismus oder verborgene Religiosität? Ein Gespräch mit Prof. Bernhard Welte", Herderkorrespondenz 30 (1976) 194.

(34) B. Welte, "Thomas von Aquin und Heideggers Gedanke von der Seinsgeschichte", en: Zeit und Geheimnis, 207. B. Welte retoma esta idea en "Gott im Denken Heideggers", en: Zeit und Geheimnis, 267 y ss. 
por este mismo camino, el pensamiento también levante su mano contra Dios y lo mate. Así, según Heidegger, la proclamación que hace Nietzsche de la muerte de Dios, es solo una consecuencia extrema de la realización del destino occidental del ser, a través del cual el pensamiento representativo de la subjetividad humana instauró su dominio" (35).

La superación de la metafísica consistirá, consecuentemente, en acoger las nuevas posibilidades epocales que se le abren al pensamiento, en pensar lo no pensado y olvidado de todo el pensamiento occidental, en volver al destino original del ser. Este será, según Heidegger, el comienzo de una superación del dominio de la metafísica: la vuelta a las raíces y a los orígenes, la atención del pensamiento al ser y a sus manifestaciones (36).

\section{EL APORTE DE LA TRADICIÓN}

En una entrevista que Welte concedió el año 1976, considera que una de las tareas más importantes del pensamiento teológico y filosófico contemporáneos, es la de poder llegar a pensar un "Dios postmetafísico". Y entiende por tal, "un Dios que no sea construible a partir de un sistema conceptual, sino que se fundamente desde experiencias originarias" (37). Lo que Welte critica al pensamiento metafísico es, justamente, su pretensión de disponer de Dios bajo la forma del concepto y de la acción. Su problema no es "la metafísica", cuanto la pretensión del hombre que en ella se ha amparado (38).

Por ello, las posibilidades de la superación de la metafísica Welte no las despliega tanto en base a autores contemporáneos, sino que, impulsado y provocado por estos, especialmente por Heidegger, recurrirá a fuentes clásicas del pensamiento católico: a Tomás de Aquino y al maestro Eckhart.

De Tomás de Aquino recoge una conocida tesis que le sirve para mostrar justamente esa diferencia entre el ser y ente: Deus non sit in aliquo genere. Esta afirmación, que se encuentra tanto en la Summa theologica, como en la Summa contra gentiles (39), permite reconocer en el mismo Tomás un discurso en relación al ser y, particularmente, en relación a Dios, que supera la márgenes estrictos del pensamiento metafísico. Escribe Welte, "si como se ha dicho por genera se comprenden los modos según los cuales se puede decir algo de algo, de acuerdo a los

(35) B. Welte, "Gott im Denken Heideggers", en: Zeit und Geheimnis, 269

(36) En su Carta sobre el humanismo, por ejemplo, M. Heidegger escribe: "Damit wir erst lernen, das genannte Wesen des Denken rein zu erfahren und das heibt zugleich zu vollziehen, müssen wir uns frei machen von der technischen Interpretation des Denkens. Deren Anfänge reichen bis zu Plato und Aristoteles zurück. Das Denken selbst gilt dort als eine tecnh, das Verfahren des Überlegens im Dienste des Tuns und Machens" (M. Heidegger, Brief über den "Humanismus", en: M. Heidegger, Wegmarken, Vittorio Klostermann, Frankfurt a. M. ${ }^{2} 1978,312$ ).

(37) B. Welte, "Atheismus oder verborgene Religiosität? Ein Gespräch mit Prof. Bernhard Welte", Herderkorrespondenz 30 (1976) 194.

(38) Sobre las posibilidades de este retorno a los orígenes y fundamentos de la metafísica he escrito en La verdadera religión. Un diálogo con Bernhard Welte, Universidad Católica del Maule: Colección Tabor $\mathrm{N}^{\circ} 18$, Talca 2000 .

(39) S.th. I. 3. 5; S.c.gent. I, 25. 
modos según los cuales algo puede ser, entonces los genera son los modos del ente. Pero, la frase dice: Deus non est in genere; de ningún modo Él es un ente. Lo mismo se puede decir aún más radicalmente: Dios no "es". Esto significa: aquello, el ser, no adviene a Dios. ¿Por qué no? Porque Él, antes de cualquier advenimiento, "es" ser" (40).

Otro camino que en Welte converge para llegar al origen y fundamento de la metafísica lo constituye el pensamiento del maestro Eckhart que, como está dicho, fue un tema importante en los diálogos que Welte sostuvo con Heidegger, especialmente en los últimos años de vida de este. A Welte le parecerá fascinante el camino especulativo y espiritual que propone Eckhart: este parte del despojamiento de toda imagen, representación y concepto; continúa con el despojamiento de todo querer, saber y tener; y concluye con el despojamiento también de "Dios". Pero este punto de llegada es también aquel que posibilita un nuevo punto de partida: el del encuentro con la cercanía trascendente del misterio de Dios, quien no se deja reducir a ningún concepto, a ningún querer, ni saber, ni tener... en los que estamos tan empeñados.

Pero esta trascendencia de Dios y este camino de despojamiento se deben poder decir y, de hecho, lo hacemos. El silencio no es la última palabra. Es así como la vía negativa y la analogía se mostrarán como caminos posibles y necesarios para volver al fundamento de la metafísica, para pensar no solo el ente, sino el ser de todo ente. En efecto, dirá Welte, la analogía -tal como la entendió Tomás-, no es un truco del intelecto para apoderarse de Dios por medio del pensamiento. Ella es, más bien, un camino hacia el misterio de la plenitud, más allá de todas las fuerzas y de todas las posibilidades del comprehender y del tener" (41). Por esta razón, cuando Welte habla de analogía no solo afirma la similitud que se expresa en el logos, sino también la diferencia que en él se manifiesta, la alteridad a la que él remite. Y para que esta alteridad propia de la analogía no se desdibuje, considera necesario introducir el concepto de analogía heteróloga (42).

De este modo, Welte recoge los impulsos que plantea el pensamiento de Heidegger, pero estos los lee, interpreta y desarrolla a partir de otras grandes figuras de la tradición filosófica y teológica. Así lo aprecia el mismo Heidegger y se lo hace saber cuando su coterráneo cumplía sesenta años: "Usted ha logrado en una larga preparación una nueva forma de la docencia en teología, que permite una discusión positiva con la época contemporánea y a la vez mantiene despierta la mirada a las grandes figuras en la tradición del pensar teológico. De esta forma -valora Heide-

(40) B. Welte, "Thomas von Aquin und Heideggers Gedanke von der Seinsgeschichte", en: Zeit und Geheimnis, 213. En un artículo del año 1968, que se concentra más expresamente en el concepto de Dios, Welte expondrá estas mismas ideas: "Bemerkungen zum Gottesbegriff des Thomas von Aquin", en: Zeit und Geheimnis, 220 y ss. Véase también: Meister Eckhart, 96 y ss.

(41) B. Welte, "Bemerkungen zum Gottesbegriff des Thomas von Aquin", en: Zeit und Geheimnis, 225. En otro texto, donde también aborda el tema de las posibilidades de la razón para conocer y formular predicados sobre Dios, Welte afirma que, para que ello sea posible, la razón se debe transitar, primero, por la via negationis, solo así se le abre a ella la via affirmationis et eminentiae" (B. Welte, "Zur Lage der Fundamentaltheologie heute", en: Auf der Spur des Ewigen, 310).

(42) Me permito remitir a mi estudio: La verdadera religión: Un diálogo con Bernhard Welte, Universidad Católica del Maule: Colección Tabor $N^{\circ}$ 18, Talca 2000, 237 y ss. 
gger- se puede salvar del mejor modo al espíritu especulativo en contra del embate de formas nuevas y menos masivas del positivismo" (43).

\section{LA APERTURA DEL SER}

Cuando el pensamiento no se constituye desde el sujeto y desde su afán por representar y disponer de Dios bajo la forma de enunciados categoriales, entonces allí comienza a abrirse para él la posibilidad de reconocer al ser en aquella región donde él mismo se muestra y manifiesta. En esta región, que Heidegger llama de la "apertura del ser", para el hombre será posible hacer la experiencia de lo santo, de lo divino, del Dios divino, ya no como construcción de su pensamiento, sino como iluminación y cercanía del ser.

Conviene advertir que esta cercanía de la dimensión de lo santo es solo posible desde lo santo y, por tanto, permanece como lo indisponible para el hombre. Heidegger piensa que "quizás lo más destacable de este tiempo sea el retraimiento de la dimensión de lo santo. Quizás sea esta la única desgracia” (44).

De este modo, como bien nota Welte, la determinación de lo santo en Heidegger, se remite a lo que primero se muestra como nada y luego como ser, y, así, remite al Dios divino. Pero, en esta referencia, lo santo es la "huella hacia la divinidad. La huella remite a la divinidad de Dios, da testimonio de ella, pero de un modo tal, que Dios mismo no se muestra" (45).

Es así que Heidegger puede reconocer en la misma muerte el misterio del ser: "La muerte -escribe- es el relicario de la nada, a saber, de aquello que en ningún sentido nunca es meramente algo que es, pero que, sin embargo, se presenta; y se presenta como el misterio del ser mismo. La muerte, como relicario de la nada, entraña en sí el hacerse presente del ser. Como relicario de la nada, la muerte es la custodia del ser" (46). Y porque Welte sabía que para Heidegger estas no eran simples "palabras bonitas", se las recuerda al momento de "confiar el cuerpo a la tierra" (47) y las quiere hacer hablar a los que allí estuvieron presentes: "La custodia del ser: la muerte entonces entraña y oculta algo. Su nada no es nada. Entraña y oculta la meta de todo el camino. Meta que aquí es denominada el ser" (48).

En definitiva, Welte nos ayuda a descubrir que la cuestión de Dios en Heidegger no se resuelve con la antinomia ateísmo-teísmo, nos ayuda a pensar que en Heidegger lo decisivo es buscar, es ponerse en camino; nos ayuda a reconocer y a valorar con qué cuidado, perseverancia y precisión este pensador ha mantenido

(43) Carta de Martin Heidegger a Benhard Welte, Freiburg, 28 de marzo de 1966. En: Universidad Iberoamericana (ed.), Martin Heidegger. Cartas a Max Müller y Bernhard Welte, Universidad Iberoamericana, México 1996, p. 93.

(44) M. Heidegger, Brief über den "Humanismus”, en: M. Heidegger, Wegmarken, Vittorio Klostermann, Frankfurt a. M. ${ }^{2} 1978,348$.

(45) B. Welte, “Gott im Denken Heideggers", en: Zeit und Geheimnis, 275.

(46) M. Heidegger, Vortrage und Aufsatze, Pfullingen, 1954, 177.

(47) B. Welte, "Buscar y encontrar. Palabras en el entierro, el 28 de mayo de 1976", en: http:// www.heideggeriana.com.ar/comentarios/welte.htm

(48) B. Welte, "Buscar y encontrar...", loc. cit. 
abierta la cuestión, ha abierto los oídos interiores del pensamiento y con qué delicadeza va dando pasos; nos ayuda a reconocer cómo Heidegger está tan alejado de cualquier tipo de ateísmo superficial, como de todo tipo de superficial teísmo; nos ayuda a disipar la pretensión que a veces ingenua o interesadamente se oculta en el teísmo y que piensa que con la cuestión sobre Dios se puede concluir fácil y rápidamente (49).

Al concluir quisiera hacer mía aquella frase que Welte escribe a Heidegger, y que citábamos más arriba: no estoy seguro si con mi interpretación estoy siempre en el camino correcto. Pero, tal vez, es más importante pensar y pensar-con que una seguridad constatable. Es lo que hemos aprendido de Heidegger y de Welte, especialmente cuando nuestro pensamiento escucha el llamado "a cargar sobre sí, pensando, la miseria del tiempo de la lejanía de Dios, y, a la vez, a interpretar el camino del tiempo y del mundo como un camino hacia Él” (50).

\title{
RESUMEN
}

Al concluir su labor como profesor de filosofía de la religión en la Universidad de Freiburg, Bernhard Welte quiso "terminar con el mismo pensamiento en cuya cercanía la había comenzado", a saber, con el pensamiento de Martín Heidegger. Para ello escribió un texto que tituló "Dios en el pensamiento de Heidegger". A la luz de este texto de Welte, este artículo se pregunta cómo en el pensamiento de Heidegger algo así como "Dios" se muestra en el ser de todo cuanto es, cómo la "luz del ser" se manifiesta como condición de posibilidad para llegar a ser auténticos sujetos en el acontecimiento de una posible revelación del Dios divino y bajo qué condiciones es posible reconocer en el "Dios postmetafísico" una respuesta plausible a las preguntas epocales por el ser.

Palabras clave: Dios, ser, metafísica, Heidegger, Welte.

\begin{abstract}
Upon concluding his work as a professor of the philosophy of religion at the University of Freiburg, Bernhard Welte wanted to "end with the same thought in proximity to which [this work] had begun", that is, with the thought of Martin Heidegger. For this purpose he wrote a text which carried the title, "God in the Thought of Heidegger." In the light of this text of Welte's, this article wonders about how, in Heidegger's thinking, something like "God" shows itself in the being of all as is, how the "light of being" manifests itself as a condition of possibility in order to arrive at being authentic subjects in the event of a possible revelation of the divine God, and under what conditions it is possible to recognize in the "post-metaphysical God" a plausible answer to the historical questions about being.
\end{abstract}

Key words: God, Being, Metaphysics, Heidegger, Welte.

(49) B. Welte, "La cuestión de Dios...", art. cit., 42.

(50) B. Welte, Mi último encuentro con Heidegger, loc. cit. 
